\title{
Changes in the phenolic content of low density lipoprotein after olive oil consumption in men. A randomized crossover controlled trial
}

\author{
Eva Gimeno ${ }^{1}$, Karina de la Torre-Carbot ${ }^{1}$, Rosa M. Lamuela-Raventós ${ }^{1}$, Ana I. Castellote ${ }^{1}$, Montserrat Fitó ${ }^{2}$, \\ Rafael de la Torre ${ }^{2}$, María-Isabel Covas ${ }^{2}$ and M. Carmen López-Sabater ${ }^{1 *}$ \\ ${ }^{1}$ Department of Nutrition and Food Science, Reference Center in Food Technology, Faculty of Pharmacy, University of Barcelona. \\ Avda. Joan XXIII s/n, 08028 Barcelona, Spain \\ ${ }^{2}$ Lipids and Cardiovascular Epidemiology Unit, Institut Municipal d' Investigació Mèdica (IMIM-Hospital del Mar), C. Doctor \\ Aiguader, 88, 0800, Barcelona, Spain
}

(Received 05 December 2006 - Revised 15 May 2007 - Accepted 18 May 2007)

Olive oil decreases the risk of CVD. This effect may be due to the fatty acid profile of the oil, but it may also be due to its antioxidant content which differs depending on the type of olive oil. In this study, the concentrations of oleic acid and antioxidants (phenolic compounds and vitamin E) in plasma and LDL were compared after consumption of three similar olive oils, but with differences in their phenolic content. Thirty healthy volunteers participated in a placebo-controlled, double-blind, crossover, randomized supplementation trial. Virgin, common, and refined olive oils were administered during three periods of 3 weeks separated by a 2 -week washout period. Participants were requested to ingest a daily dose of $25 \mathrm{ml}$ raw olive oil, distributed over the three meals of the day, during intervention periods. All three olive oils caused an increase in plasma and LDL oleic acid $(P<0 \cdot 05)$ content. Olive oils rich in phenolic compounds led to an increase in phenolic compounds in LDL $(P<0 \cdot 005)$. The concentration of phenolic compounds in LDL was directly correlated with the phenolic concentration in the olive oils. The increase in the phenolic content of LDL could account for the increase of the resistance of LDL to oxidation, and the decrease of the in vivo oxidized LDL, observed in the frame of this trial. Our results support the hypothesis that a daily intake of virgin olive oil promotes protective LDL changes ahead of its oxidation.

Olive oil: Oleic acid: Phenolic compounds: LDL: CVD risk

CVD is the main cause of death and disability in developed countries $^{1-3}$. The type of fat consumed can modify the plasma and LDL lipid profile, which is directly related to the growth of atheroma plaque $e^{4,5}$. However, the antioxidant content of the diet is also crucial, as oxidized LDL seems to be involved in atherosclerotic plaque development ${ }^{6}$.

Olive oil, rich in MUFA and antioxidant minor components, is considered to be favourable for cardiovascular health ${ }^{7-12}$. Linoleic acid (C18: 2) accounts for $90 \%$ of the PUFA present in LDL and is the main substrate for oxidation. However, diets rich in oleic acid, like those in Mediterranean countries, generate LDL particles which appear to be more resistant to oxidation $^{3,5,13-17}$. Moreover, data from in vitro ${ }^{18,19}$ and in vivo studies $^{20-23}$ show that the phenolic compounds of olive oil protect LDL from lipid peroxidation. Thus, olive oil phenolic compounds are good candidates to partially account for the prevention provided by diet against CVD. Due to this, studies directed at a better understanding of the protective mechanisms of olive oil on human health must be enhanced.

To date, few studies have analysed the effects of sustained olive oil consumption on human LDL composition. The few available data come from short-term studies ${ }^{20,24,25}$ or non-randomized trials where only virgin olive oil was used ${ }^{25}$. A double-blind, randomized, crossover, controlled trial was carried out to identify the effect of similar olive oils, but with a range of phenolic content, on the levels of plasma and LDL antioxidants and oleic acid in healthy subjects. Volunteers from a religious centre, a population with regular and similar lifestyles such as physical activity and dietary habits, were involved. In the frame of this trial we have previously reported ${ }^{21}$ a protective effect of an olive oil rich in phenolic compounds on LDL oxidation. From these results, our main hypothesis was that sustained real-life doses $(25 \mathrm{ml} / \mathrm{d})$ of raw rich phenolic olive oil could enhance the antioxidant load of the LDL, thus protecting the lipoproteins from oxidation. Here, we examined the fatty acid and antioxidant composition of the LDL after consumption of similar olive oils, but with differences in their phenolic content, in order to test our hypothesis.

\section{Materials and methods}

Study population

An in-person screening visit was conducted to ascertain eligibility and obtain baseline data. Forty-two subjects from a religious community were screened for inclusion. Nine of them were ineligible. Thus, thirty-three healthy volunteers, from 23 to 91 years old, with a regular lifestyle and dietary habits

Abbreviations: CAE, caffeic acid equivalents; FAME, fatty acid methyl esters

* Corresponding author: Dr M. Carmen López Sabater, fax +34-93 40359 31, email mclopez@ub.edu 
were included. The volunteers gave their written consent prior to participating in the study. Subjects with any of the following conditions were excluded: smoking; intake of any drug or supplements with established antioxidative properties, either in the two weeks before the onset of the study or throughout the study; obesity (BMI $>30 \mathrm{~kg} / \mathrm{m}^{2}$ ); diabetes; and any disease or condition that would impair compliance.

Diets were prepared and consumed in the religious centre. Subjects maintained their regular physical activity and lifestyle throughout the study. The local institutional Review Board approved the protocol according to the Helsinki Declaration of 1975.

\section{Olive oil composition}

Three olive oils provided by the Olive Oil Cooperative Association of Catalonia were used. They were obtained from the same harvest which means that olive fruits were of the same cultivar, collection time, and soil. First, a virgin olive oil with a phenolic content of $825 \mu \mathrm{mol}$ caffeic acid equivalents $(\mathrm{CAE}) / \mathrm{kg}$ was selected. Then, we used a refined (phenolic content of $0 \mu \mathrm{mol} / \mathrm{kg}$ ) and a common olive oil (phenolic content of $370 \mu \mathrm{mol} \mathrm{CAE} / \mathrm{kg}$ ) with similar fatty acid composition, $\alpha$-tocopherol and $\beta$-carotene content, in order to match the virgin olive oil. Major and minor components of the three olive oils were examined in order to confirm their similar fatty acid and micronutrient profile, as well as the differences in their phenolic content. The characteristics of the oils are summarized in Table 1. The acidity value, the peroxide index, and the UV spectrophotometric index $\left(\mathrm{K}_{270}\right)$ were determined following the analytical methods described in the European Union Commission Regulation CE/1989/200326. Fatty acids were transformed into methyl esters and analyzed by gas chromatography ${ }^{26}$. $\alpha$-Tocopherol was measured by HPLC, as previously described ${ }^{27}$. Phenolic compounds were measured by the Folin-Ciocalteau method ${ }^{25,28,29}$.

Table 1. Olive oil composition

\begin{tabular}{|c|c|c|c|}
\hline & Refined & Common & Virgin \\
\hline \multicolumn{4}{|l|}{ Quality parameters } \\
\hline Free acidity (\% oleic acid) & 0.12 & 0.17 & 0.11 \\
\hline Peroxide value (meq $\mathrm{O}_{2} / \mathrm{kg}$ oil) & $1 \cdot 80$ & 2.93 & $6 \cdot 48$ \\
\hline $\mathrm{K}_{270}$ & 0.480 & 0.201 & 0.102 \\
\hline \multicolumn{4}{|l|}{ Fatty acids (\%) } \\
\hline C14:0 & 0.02 & 0.02 & 0.01 \\
\hline C16:0 & 11.25 & 11.78 & $13 \cdot 18$ \\
\hline C16:1 & 0.86 & 1.05 & $1 \cdot 11$ \\
\hline $\mathrm{C} 17: 0$ & 0.08 & 0.06 & 0.10 \\
\hline C17:1 & 0.15 & 0.13 & 0.22 \\
\hline C18:0 & $2 \cdot 52$ & 2.59 & $1 \cdot 76$ \\
\hline C18:1 & 73.46 & $75 \cdot 65$ & $73 \cdot 37$ \\
\hline C18:2 & 9.97 & $7 \cdot 17$ & 9.02 \\
\hline $\mathrm{C} 20: 0$ & 0.45 & 0.39 & 0.33 \\
\hline C18:3 & 0.73 & 0.70 & 0.48 \\
\hline $\mathrm{C} 20: 1$ & 0.34 & 0.29 & 0.28 \\
\hline $\mathrm{C} 22: 0$ & 0.12 & 0.10 & 0.10 \\
\hline $\mathrm{C} 24: 0$ & 0.05 & 0.04 & 0.04 \\
\hline MUFA(\%) & 74.83 & $77 \cdot 14$ & 74.98 \\
\hline PUFA(\%) & $10 \cdot 68$ & $7 \cdot 86$ & $9 \cdot 50$ \\
\hline $\mathrm{SFA}(\%)$ & 14.49 & $15 \cdot 00$ & 15.52 \\
\hline Phenolic compounds ( $\mu \mathrm{mol} / \mathrm{kg}$ CAE) & 0 & 370 & 825 \\
\hline$\alpha$-Tocopherol (mol $/ \mathrm{kg})$ & 65.88 & $48 \cdot 22$ & $47 \cdot 98$ \\
\hline
\end{tabular}

CAE, Caffeic acid equivalents; $K_{270}$, UV spectrophotometric index.

\section{Study design}

A placebo-controlled, double-blind, crossover, randomized, supplementation trial was conducted. A Latin square for the three treatments was used in the crossover trial, to randomize participants into three orders of olive oil administration: virgin-common-refined (order 1), common-refined-virgin (order 2), and refined-virgin-common (order 3). The three olive oils were administered over three periods of 3 weeks, each one preceded by 2 -week washout periods (Fig. 1). Participants were requested to ingest a daily raw dose of $25 \mathrm{ml}$ olive oil, distributed over the three meals of the day, during intervention periods. Refined olive oil was used as source of raw fat in washout periods. Other cooking fats were replaced by refined olive oil to maintain energy and oleic acid intake unchanged during the entire study.

Daily menus were recorded, as were extra food intakes between meals, and meals eaten outside the religious centre. Participants were requested to avoid a high intake of foods containing phenolic compounds such as fruit, vegetables, tea and red wine. Participants were managed by a trained physician who stayed at the religious centre throughout the study. Participants were instructed to return the $25 \mathrm{ml}$ containers every morning when they collected their next daily dose, in order to register the amount of unconsumed oil. Treatment containers for the daily dose of olive oil to be ingested in the intervention periods were coded, concealed from participants, and distributed by investigators to the participants. Containers were opaque in order to conceal the olive oil and to avoid its degradation.

Diets were analyzed by a nutritionist and converted into nutrients using the software Medysystems (Conaycyte S.A, Madrid, Spain) ${ }^{30}$. Anthropometric variables (i.e. height and weight) were recorded. Physical activity was assessed by the Minnesota Leisure Time Physical Activity Questionnaire, which has been validated for use on Spanish men ${ }^{31}$.

\section{Sample size and power analyses}

The sample size was calculated to provide a statistical power of $80 \%$. In order to recognize as statistically significant a difference $\geq 10 \mathrm{~min}$ change in lag time, and a change of $4 \mathrm{nmol} / \mathrm{mg}$ apo B of phenolic compounds in LDL, ten and nine subjects were necessary in each order of olive oil administration respectively. It was assumed that standard deviations were $10 \mathrm{~min}$ and $4 \mathrm{nmol} / \mathrm{mg}$ apo B for lag time and phenolic compounds in LDL, respectively.

\section{Blood sampling and laboratory analyses}

Laboratory measurements were carried out on samples from fasting subjects taken: before the first washout period (baseline); before administration of the three types of oil; and after olive oil administration. To prevent oxidation and aggregation of LDL, blood samples were drawn with EDTA tubes $(1 \mathrm{~g} / \mathrm{l})$ and stored with saccharose $(0.18 \mathrm{~mm})$ at $-80^{\circ} \mathrm{C}$. Plasma was separated by centrifugation at $1000 \mathrm{~g}$ at $4^{\circ} \mathrm{C}$ for $15 \mathrm{~min}$. LDL isolation was performed by sequential flotation ultra centrifugation ${ }^{32}$. All samples were stored at $-80^{\circ} \mathrm{C}$ until analysis. 
Virgin olive oil and phenolic content of LDL

\begin{tabular}{|c|c|c|c|c|c|c|c|}
\hline & & \multicolumn{6}{|c|}{ Type of intervention (Week) } \\
\hline Order & Baseline & $\begin{array}{l}1^{\text {st }} \text { washout } \\
\text { (weeks } 1-2 \text { ) }\end{array}$ & $\begin{array}{c}1^{\text {st }} \text { olive oil } \\
\text { intervention } \\
\text { (weeks 3-5) }\end{array}$ & $\begin{array}{l}2^{\text {nd }} \text { washout } \\
\text { (weeks 6-7) }\end{array}$ & $\begin{array}{l}2^{\text {nd }} \text { olive oil } \\
\text { intervention } \\
\text { (weeks 8-10) }\end{array}$ & $\begin{array}{c}3^{\text {rd }} \text { washout } \\
\text { (weeks } \\
11-12 \text { ) }\end{array}$ & $\begin{array}{c}3^{\text {rd }} \text { olive oil } \\
\text { intervention } \\
\text { (weeks } \\
13-15 \text { ) }\end{array}$ \\
\hline 1 & \multirow{3}{*}{ B } & \multirow{3}{*}{ wo } & Virgin & \multirow{3}{*}{ wo } & Common & \multirow{3}{*}{ wo } & Refined \\
\hline 2 & & & Common & & Refined & & Virgin \\
\hline 3 & & & Refined & & Virgin & & Common \\
\hline
\end{tabular}

Fig. 1. Time-line for the study design. B, Baseline; WO, wash-out.

Total cholesterol, HDL-cholesterol and TAG levels were measured by standard enzymatic methods. The fatty acid composition of plasma and LDL was measured by the method described by Rodríguez-Palmero et al. ${ }^{33}$. Fatty acid methyl esters were prepared by alkaline hydrolysis with sodium methylate and esterification with boron trifluoride in methanol. Fatty acid methyl esters were extracted with hexane and injected into a gas chromatograph. The $\mathrm{CV}$ obtained ranged from 3.42 to $5.25 \%$. To determine $\alpha$-tocopherol in plasma and LDL, an aliquot of the sample was deproteinized with ethanol. The analyte was then extracted with hexane and injected into an HPLC system. The CV was $4 \cdot 27 \%^{34}$. Phenolic compounds in LDL were also determined by HPLC-Diode Array Detection, as previously described ${ }^{35}$. Briefly, acidulated LDL was applied to a Waters Oasis ${ }^{\text {TM }}$ HLB extraction cartridge (Milford, MA, USA) and washed with water and $5 \%$ aqueous methanol. Phenolic compounds, measured only in LDL, were eluted with methanol, which was then evaporated under a stream of nitrogen. The residue was dissolved in acidulated water and injected into an HPLC system. The chromatogram was monitored at $280 \mathrm{~nm}$ and the areas of phenolic compounds were expressed as CAE. The analytical within-run precision was $5.25 \%$, and the between-run precision was $8.8 \%$. Oxidized LDL was measured in plasma by ELISA (ox-LDL, Mercodia AB, Uppsala, Sweden). The LDL resistance to oxidation was determined by formation of conjugated dienes after copper $(5 \mu \mathrm{M})$ oxidation of isolated $\mathrm{LDL}^{18}$. Results of LDL parameters were expressed according to apo B. Apo B concentrations were measured by immunoturbidimetry (Roche Diagnostics, Basel, Switzerland).

Hydroxytyrosol and tyrosol, the major olive oil phenolic compound, were measured in urine, by HPLC, as markers of compliance of the interventions. Analytical within-run precision and between-run precision were 2.9 and $3.8 \%$, and 5.7 and $6.2 \%$ for tyrosol and hydroxytyrosol, respectively ${ }^{36}$.

\section{Statistical methods}

The normality of variable distribution was assessed by the Kolmogorov-Smirnov test and by an analysis of skewness and kurtosis. One-factor ANOVA and the Kruskal-Wallis test were used to analyze the differences in baseline characteristics among the three groups, by order of olive oil administration. A general linear model for repeated measurements, with Tukey's correction for multiple comparisons, was used to assess washout effectiveness and the effect of each type of oil. The possible carryover effect was checked by testing a period-by-treatment interaction term in the model. Statistical significance was defined as $P<0.05$ for a two-sided test. SPSS 11.0 statistical software (SPSS Inc., Chicago, IL, USA) was used.

\section{Results}

\section{Participants' characteristics}

The subject pool at randomization consisted of thirty-three subjects. Two of these were withdrawn because of a post-randomization criterion of ineligibility (hypercholesterolemia), and one participant requested to be withdrawn. Thus, finally thirty subjects participated in the study. Baseline characteristics (at the beginning of the study) of the subjects are presented in Table 2 according to the randomized order. Negligible differences in baseline characteristics were observed among the three randomly formed groups. The mean age of participants was 57.13 (SD 19.54) years and the BMI was 22.92 (SD 5.15 ) $\mathrm{kg} / \mathrm{m}^{2}$. We did not observe changes in physical activity from baseline to the end of the study.

\section{Adverse effects}

No collateral effects which could influence the participation in the study or the compliance of the participants occurred during the study period. No adverse effects were observed related to olive oil ingestion.

\section{Dietary intake and adherence}

The average of the main antioxidant (i.e. $\beta$-carotenoid, vitamin $\mathrm{C}, \alpha$-tocopherol), or pro-oxidant (i.e. Fe) intake, energy, and any nutrient of interest were similar in the three groups during each type of olive oil intervention (Table 3). Participants' alcohol intake was $<30 \mathrm{~g} / \mathrm{d}$. Tyrosol and hydroxytyrosol in urine increased in a dose-dependent manner with the phenolic content of olive oil administered. Mean changes were $15 \%, 147 \%$, and $190 \%$ for tyrosol, and $12 \%, 180 \%$, and $221 \%$ for hydroxytyrosol, after refined, common, and virgin olive oil, respectively ${ }^{21}$.

\section{Plasma and LDL fatty acid and antioxidant content}

The phenolic content of LDL was significantly higher after the virgin olive oil administration than at baseline $(P<0.005)$ and 
Table 2. Baseline characteristics by sub-groups of subjects depending on the order ${ }^{*}$ of olive oil administration (Mean values and standard deviations)

\begin{tabular}{|c|c|c|c|c|c|c|c|}
\hline \multirow[b]{2}{*}{ Clinical parameter } & \multicolumn{2}{|c|}{ Order 1} & \multicolumn{2}{|c|}{ Order 2} & \multicolumn{2}{|c|}{ Order 3} & \multirow[b]{2}{*}{$P$} \\
\hline & Mean & SD & Mean & SD & Mean & SD & \\
\hline Age (year) & 54.8 & 21.4 & $61 \cdot 0$ & $19 \cdot 2$ & $56 \cdot 6$ & $19 \cdot 3$ & 0.80 \\
\hline $\mathrm{BMI}\left(\mathrm{kg} / \mathrm{m}^{2}\right)$ & $24 \cdot 2$ & 3.5 & 23.2 & 3.3 & $23 \cdot 6$ & 2.9 & 0.22 \\
\hline Waist:hip ratio & 0.92 & 0.05 & 0.89 & 0.04 & 0.89 & 0.05 & 0.40 \\
\hline TAG $(\mathrm{mmol} / \mathrm{l})$ & $1 \cdot 1$ & 0.5 & $1 \cdot 2$ & 0.4 & 1.0 & 0.5 & 0.68 \\
\hline Total cholesterol $(\mathrm{mmol} / \mathrm{l})$ & 5.4 & $1 \cdot 1$ & $5 \cdot 7$ & 1.0 & 5.9 & 1.2 & 0.25 \\
\hline $\mathrm{HDL}$ cholesterol $(\mathrm{mmol} / \mathrm{l})$ & 1.4 & 0.3 & 1.4 & 0.3 & 1.5 & $0 . \overline{3}$ & 0.66 \\
\hline Glucose $(\mathrm{mmol} / \mathrm{l})$ & 4.4 & 0.7 & 4.2 & 0.5 & 4.6 & 0.9 & 0.59 \\
\hline Plasma $\alpha$-tocopherol $(\mu \mathrm{mol} / \mathrm{ml})$ & $4.2 \times 10^{-2}$ & $1.38 \times 10^{-2}$ & $4.7 \times 10^{-2}$ & $1.2 \times 10^{-2}$ & $5.1 \times 10^{-2}$ & $1.1 \times 10^{-2}$ & 0.22 \\
\hline Plasma oleic acid (mmol/l) & $2 \cdot 1$ & 0.5 & $2 \cdot 0$ & 0.9 & $2 \cdot 0$ & 0.6 & 0.77 \\
\hline LDL $\alpha$-tocopherol $(\mu \mathrm{mol} / \mathrm{mg}$ apo B) & $2.1 \times 10^{-2}$ & $0.31 \times 10^{-2}$ & $1.9 \times 10^{-2}$ & $0.38 \times 10^{-2}$ & $1.7 \times 10^{-2}$ & $0.45 \times 10^{-2}$ & 0.59 \\
\hline LDL phenolic compounds (nmol CAE/mg apo B) & 8.7 & 3.2 & $7 \cdot 9$ & $2 \cdot 3$ & $7 \cdot 8$ & 1.5 & 0.29 \\
\hline LDL oleic acid $(\mu \mathrm{mol} / \mathrm{mg}$ apo B) & 0.31 & 0.1 & 0.25 & 0.05 & 0.31 & 0.1 & 0.34 \\
\hline Physical activity $(\mathrm{kJ} / \mathrm{d})$ & 1410 & 966 & 1648 & 879 & 1886 & 1518 & 0.62 \\
\hline
\end{tabular}

CAE, Caffeic acid equivalents.

* Orders of olive oil administration: Order 1, virgin-common-refined ( $n$ 11); Order 2, common-refined-virgin $(n$ 9); Order 3, refined-virgin-common ( $n$ 10).

pre-virgin olive oil consumption $(P<0 \cdot 01)$, without significant changes after refined or common olive oil interventions (Table 4 and Fig. 2). When the relative changes (as percentage) were assessed, phenolic compounds in LDL followed an increasing trend $(P<0.05)$ from refined to common to virgin olive oil. The increase in phenolic compounds in LDL after virgin olive oil intervention reached significance $v$. that after refined olive oil intervention $(P<0.005)$.

We did not observe any changes in oleic acid and $\alpha$-tocopherol in plasma or in $\alpha$-tocopherol in LDL among olive oil interventions. In comparison with baseline values, levels of oleic acid increased after common and virgin olive oil interventions (Table 4). No carryover effect was observed in any variable of interest, with the exception of oleic acid in plasma and LDL. As expected, an increase in the timesequence for oleic acid values was observed $(P<0.05)$. As has been previously described, a protective effect of olive oil phenolic compounds on LDL oxidation was observed ${ }^{21}$. The resistance of LDL to oxidation induced by copper lag time for copper-mediated LDL oxidation increased, and the levels of in vivo oxidized LDL decreased in a dose-dependent manner with the phenolic content of the olive oil administered $(P<0.05)$. Mean changes were $3.2 \%,-5.2 \%$, and $-28.2 \%$ for in vivo oxidized LDL, and $2 \cdot 3,4.5 \%$, and $5.5 \%$ for the in vitro lag time of LDL oxidation, after refined, common, and virgin olive oil, respectively. Changes in the lipid profile after the olive oil interventions are reflected in Fig. 3. An increase in HDL cholesterol after virgin olive oil consumption was observed $(P=0 \cdot 029)^{21}$.

\section{Discussion}

In Mediterranean countries, dietary fat accounts for more than the $30 \%$ of energy mostly provided by the MUFA from olive oil. The main olive oils used for dietary purposes in Mediterranean countries are virgin olive oil, obtained exclusively by physical procedures and rich in phenolic compounds, and common olive oil ${ }^{26}$ which is a mixture of refined

Table 3. Daily intake of nutrients in each dietary period (Mean values and standard deviations for thirty subjects)

\begin{tabular}{|c|c|c|c|c|c|c|c|}
\hline & \multicolumn{6}{|c|}{ Olive oil administered } & \multirow[b]{3}{*}{$P$} \\
\hline & \multicolumn{2}{|c|}{$\begin{array}{c}\text { Refined } \\
(0 \mathrm{mg} / \mu \mathrm{mol} / \mathrm{kg} \mathrm{CAE})\end{array}$} & \multicolumn{2}{|c|}{$\begin{array}{c}\text { Common } \\
(370 \mu \mathrm{mol} / \mathrm{kg} \mathrm{CAE})\end{array}$} & \multicolumn{2}{|c|}{$\begin{array}{c}\text { Virgin } \\
(825 \mu \mathrm{mol} / \mathrm{kg} \mathrm{CAE})\end{array}$} & \\
\hline & Mean & $\mathrm{SD}$ & Mean & SD & Mean & SD & \\
\hline Energy (kJ) & 9567 & 937 & 9639 & 1079 & 9668 & 966 & 0.84 \\
\hline Protein (\%) & 20.4 & 1.8 & $20 \cdot 2$ & $1 \cdot 8$ & $20 \cdot 3$ & 1.6 & 0.70 \\
\hline Fat $(\%)$ & 37.5 & $4 \cdot 1$ & 37.7 & 4.5 & $40 \cdot 0$ & $4 \cdot 8$ & 0.60 \\
\hline Carbohydrate (\%) & 41.9 & $5 \cdot 1$ & $41 \cdot 8$ & 4.9 & 41.6 & 5.5 & 0.89 \\
\hline MUFA (\%) & $20 \cdot 2$ & $2 \cdot 8$ & $20 \cdot 1$ & 2.9 & $20 \cdot 2$ & $2 \cdot 8$ & 0.96 \\
\hline PUFA (\%) & 4.5 & 0.5 & 4.4 & 0.5 & 4.4 & 0.4 & 0.55 \\
\hline SFA (\%) & 13.9 & $2 \cdot 0$ & 13.9 & $2 \cdot 2$ & $13 \cdot 8$ & 1.9 & 0.82 \\
\hline$\alpha$-tocopherol (mg) ${ }^{*}$ & $8 \cdot 4$ & 1.9 & $8 \cdot 3$ & 2.4 & $8 \cdot 6$ & $2 \cdot 3$ & 0.66 \\
\hline Vitamin C (mg) & 227 & 99 & 228 & 102 & 229 & 97 & 0.75 \\
\hline Phenolic compounds $(\mathrm{mg})^{\star}$ & $14 \cdot 9$ & 4.8 & $14 \cdot 4$ & $5 \cdot 3$ & $14 \cdot 7$ & $5 \cdot 8$ & 0.66 \\
\hline$\beta$-Carotene $(\mu \mathrm{g})$ & 2385 & 354 & 2337 & 361 & 2420 & 332 & 0.74 \\
\hline
\end{tabular}

CAE, phenolic content in caffeic acid equivalents.

* This amount excludes the phenolic compounds and $\alpha$-tocopherol taken with the oils studied. 
Table 4. Content in $\alpha$-tocopherol, phenolic compounds and oleic acid at baseline and after each dietary period (Mean values and standard deviations for thirty subjects)

\begin{tabular}{|c|c|c|c|c|c|c|c|c|}
\hline & \multicolumn{2}{|c|}{ Baseline } & \multicolumn{2}{|c|}{$\begin{array}{l}\text { Post-consumption of } \\
\text { refined olive oil }\end{array}$} & \multicolumn{2}{|c|}{$\begin{array}{l}\text { Post-consumption of } \\
\text { common olive oil }\end{array}$} & \multicolumn{2}{|c|}{$\begin{array}{l}\text { Post-consumption of } \\
\text { virgin olive oil }\end{array}$} \\
\hline & Mean & SD & Mean & SD & Mean & SD & Mean & SD \\
\hline \multicolumn{9}{|l|}{ Plasma } \\
\hline$\alpha$-Tocopherol $(\mu \mathrm{mol} / \mathrm{ml})$ & $4.8 \times 10^{-2}$ & $1.1 \times 10^{-2}$ & $4.6 \times 10^{-2}$ & $1.2 \times 10^{-2}$ & $4.4 \times 10^{-2}$ & $1.5 \times 10^{-2}$ & $4.4 \times 10^{-2}$ & $1.1 \times 10^{-2}$ \\
\hline Oleic acid $(\mathrm{mmol} / \mathrm{l})$ & 2.02 & $0 \cdot 10$ & 2.05 & 0.07 & $2 \cdot 12$ & 0.07 & 2.05 & 0.10 \\
\hline \multicolumn{9}{|l|}{ LDL } \\
\hline $\begin{array}{l}\text { Phenolic compounds } \\
\text { (nmol CAE /mg apo B) }\end{array}$ & $7 \cdot 88$ & 2.55 & $9 \cdot 16$ & $3 \cdot 7$ & 9.55 & $4 \cdot 27$ & $10 \cdot 44^{*} \dagger$ & $4 \cdot 0$ \\
\hline Oleic acid ( $\mu \mathrm{mol} / \mathrm{mg}$ apo B) & 0.31 & 0.14 & 0.32 & 0.12 & $0.39^{\star}$ & 0.14 & 0.39 & 0.14 \\
\hline
\end{tabular}

${ }^{*}$ Mean values were significantly different from baseline values $(P<0.005)$

$+P<0.05$ for linear trend from refined to common to virgin olive oil.

(phenolic-free) and virgin olive oil. In this study, and using three types of olive oil with high (virgin), medium (common), and null (refined) phenolic content, we observed an increase in the LDL phenolic compound content of healthy human volunteers, in a dose-dependent manner with the phenolic content of the olive oil administered. This increase in the phenolic content of the LDL was concomitant with a decrease of the in vivo degree of LDL oxidation, and an increase in the ex vivo resistance of LDL to oxidation. A dose-dependent decrease of the oxidative lipid damage with the phenolic content of the olive oil has been recently reported ${ }^{20}$. Plasma concentration of oxidized LDL has been shown to be predictive for CVD events in a general population ${ }^{37}$. Thus, interventions directed at controlling this variable are useful tools in the primary and secondary prevention of CVD.

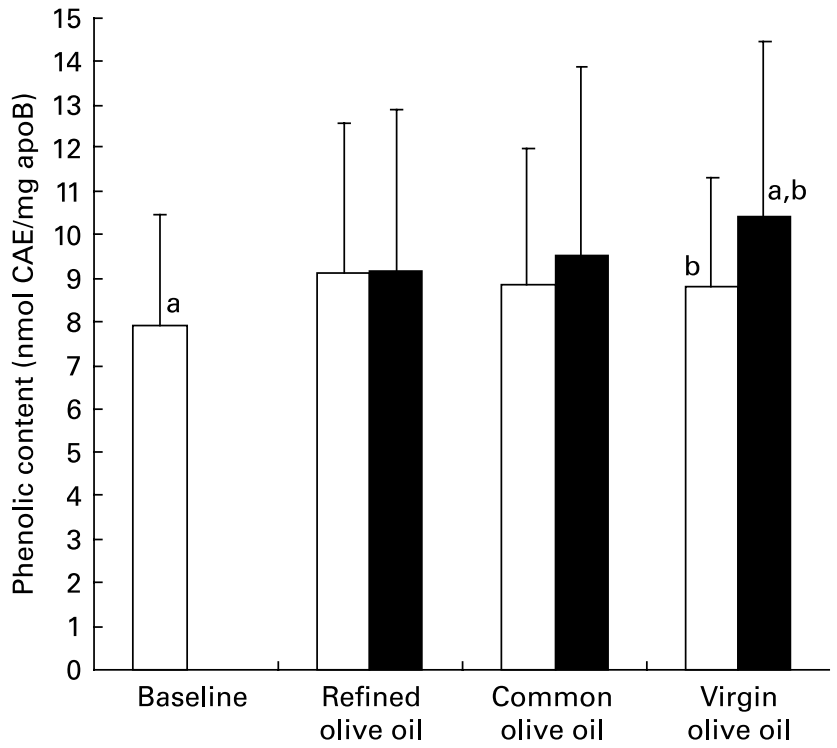

Fig. 2. Phenolic content in LDL at the beginning of the study (baseline) and before $(\square)$ and after $(\square)$ each olive oil intervention. Values are means with their standard deviations shown by vertical bars. CAE, caffeic acid equivalents. Mean values were significantly different from those at baseline after the virgin olive oil administration ${ }^{a}(P<0.005)$. Mean values were significantly different between pre- and post- virgin olive oil consumption ${ }^{\mathrm{b}}(P<0.01)$.
As is reflected in this study and others, olive oil phenolic compounds are absorbed in human subjects ${ }^{38-41}$ in a dosedependent manner with the phenolic content of the olive oil $^{20,21,42}$. Phenolic compounds from olive oil can bind the human LDL after virgin olive oil ingestion ${ }^{43,44}$. In a previous study, we observed that the postprandial LDL total phenolic content and LDL oxidation could be modulated by olive oil phenolic compounds in human subjects ${ }^{20}$. Here, we report the same phenomenon after a sustained consumption of olive oil.

At baseline, subjects did not consume only olive oil as a source of fat. Instead, they consumed preferentially other vegetable oils for cooking, using olive oil for raw purposes. The increase in oleic acid in LDL observed throughout the study could be due to the consumption of all types of olive oil, given that the refined olive oil was consumed during the washout periods. From our results, olive oil consumption promoted an increase of MUFA in the LDL. MUFA are less susceptible to oxidation than $\mathrm{PUFA}^{3,45}$. Due to this, the increase of MUFA in LDL could enhance the preservation of the phenolic compounds bound to LDL, given that they are not used to counteract the autocatalytic chain reaction of LDL fatty acid peroxidation $^{46}$. This fact could also explain the non-significant increase in LDL phenolic compounds observed after refined olive oil intervention, compared with baseline values.

Phenolic compounds can protect LDL from oxidation $^{20,21,44,47-50}$ through different mechanisms: (1) for the free radical scavenging properties (the capacity of hydrogendonation and their ability to improve radical stability) $)^{51-53}$; (2) by means of the strong metal-chelation capacity ${ }^{54}$; (3) through the nitric oxide stimulation in endothelial cells ${ }^{55,56}$; (4) by stimulating antioxidant transcription and detoxification defence systems ${ }^{42,57,58}$, and (5) by modulating other enzymatic systems related with oxidation process (cyclooxygenases, lipooxigenases and $\mathrm{NAD}(\mathrm{P}) \mathrm{H}$ oxidase $)^{53}$. In addition, olive oil phenolic compounds have been shown to be related with the prevention of platelet aggregation ${ }^{49,59}$, vasodilatation $^{22}$, and anti-inflammation $22,59-61$, Thus, the protection provided by the olive oil phenolic compounds on CVD risk may be due to a combination of bioactive mechanisms.

Phenolic compounds of dietary origin have been shown to be involved in cholesterol and lipoprotein metabolism ${ }^{60}$. 


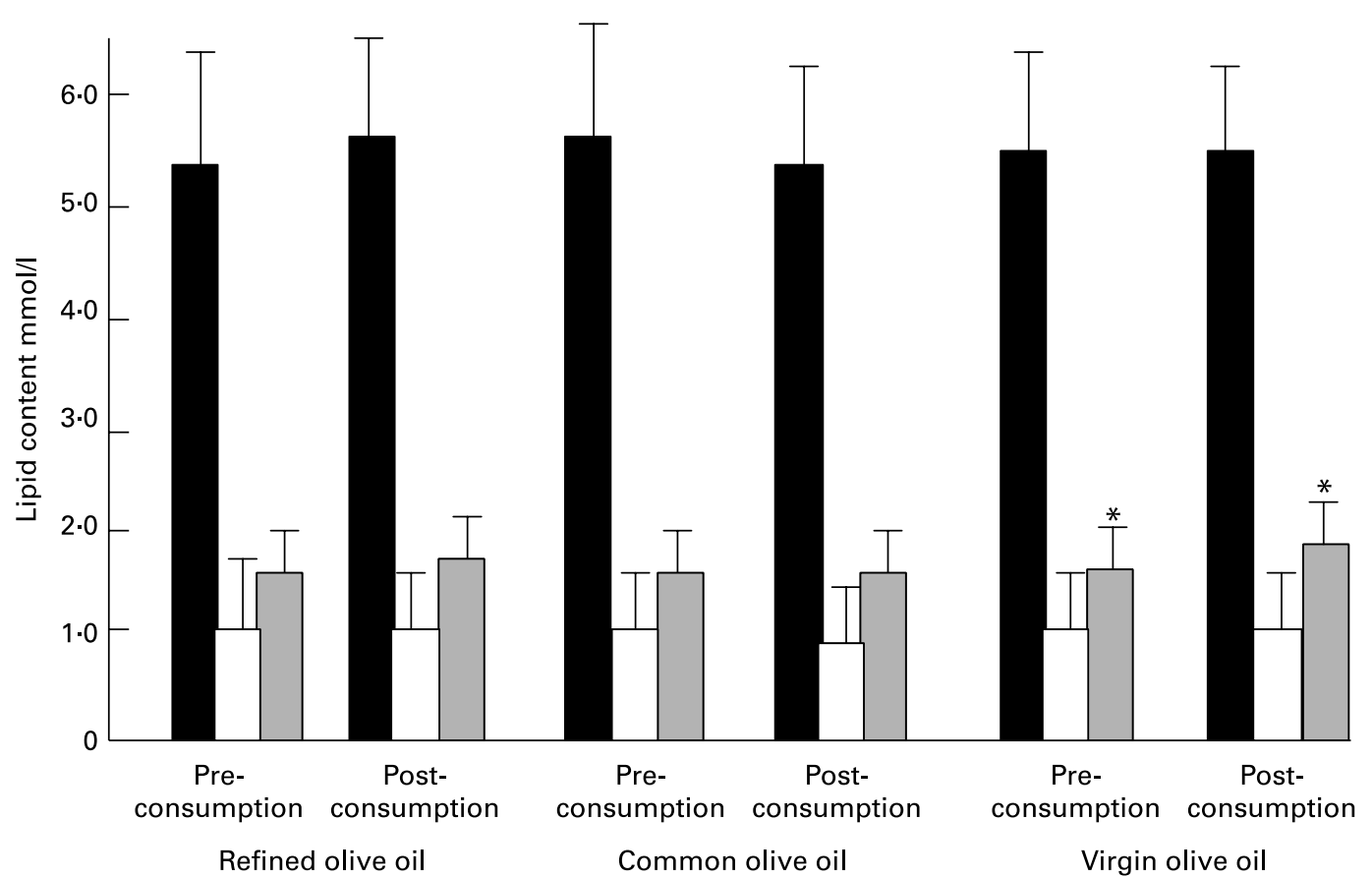

Fig. 3. Levels of total cholesterol ( $\square$ ), HDL cholesterol ( $\square$ ), and TAG ( $\square$ ). Values are means with standard deviations shown by vertical bars. Mean values were significantly different between pre- and post-consumption ${ }^{*} P=0.029$.

In this study, we observed an increase in HDL cholesterol levels after virgin olive oil intervention. These results are in line with the recent results of the EUROLIVE study ${ }^{62}$, a large inter-country intervention trial with three similar types of olive oils, but with differences in their phenolic content. Results of the EUROLIVE study showed a dose-dependent increase of the plasma HDL cholesterol levels with the phenolic content of the olive oil administered. Mechanisms by which phenolic compounds can enhance HDL cholesterol are at present unknown.

Phenolic compounds in olive oil may contribute to the health benefits ${ }^{63,64}$ and a Mediterrranean diet, rich in virgin olive oil, improves protection against the major risk factors for $\mathrm{CVD}^{65,66}$.

The design and conduct of the study had strengths and limitations. One strength was that the dose administered, $25 \mathrm{ml} / \mathrm{d}$, closely reflects real-life consumption in Southern European Mediterranean countries. Another was the crossover design, which permitted the same participants to receive all olive oils, thereby minimizing interferences with confounding variables. Our design, however, did not allow modelling the first- and second-order possible carryover effects. Another limitation was the inability to assess potential interactions between olive oil and other diet components. Measurements of dietary intake relied on self-reporting and were, therefore, subjective. Another limitation is the short duration of the intervention periods. It is unknown whether additional or different effects would have been observed over longer periods. A longer duration of the study, however, could have impaired the compliance of the participants. Also, although the trial was blinded, some participants might have identified the refined olive oil by its taste and smell.

In summary, regular consumption of olive oil increases the MUFA content of the LDL lipoprotein. Regular consumption of olive oil rich in phenolic compounds increases the LDL total phenolic content in a dose-dependent manner with the phenolic content. The combined protective effect of the MUFA and phenolic content of the LDL could account for the decrease in LDL oxidation observed in the frame of this study.

\section{Acknowledgements}

We thank Robin Rycroft for revising the English manuscript; the members of the religious centre for generously agreeing to participate in this study; Helmut Schroeder for the dietary analysis; the Spanish Ministry of Science and Technology (project SAF2004-08173-C03-03), and the Spanish Ministry of Health (CIBER: CB06/02/0079) for their financial support; the University of Barcelona for the grant received by K.T.-C; and the Olive Oil Cooperative Association of Catalonia for providing the olive oil.

\section{References}

1. Shaefer EJ (2002) Lipoprotein, nutrition, and heart disease. Am J Clin Nutr 75, 191-212.

2. Sans S, Kesteloot H \& Kromhout D (1997) The burden of cardiovascular diseases mortality in Europe. Task Force of the European Society of Cardiology on Cardiovascular Mortality and Morbidity Statistics in Europe. Eur Heart J 18, 1231-1248.

3. Kratz M, Cullen P, Kannenberg F, Kassner A, Fobker M, Abuja PM, Assmann G \& Wahrburg U (2002) Effects of dietary fatty acids on the composition and oxidizability of low-density lipoprotein. Eur J Clin Nutr 56, 72-81.

4. Connor WE (1996) The decisive influence of diet on the progression and reversibility of coronary heart disease. Am J Clin Nutr 64, 253-254. 
5. Perez-Jimenez F, Lopez-Miranda J \& Mata P (2002) Protective effect of dietary monounsaturated fat on arteriosclerosis: beyond cholesterol. Atherosclerosis 163, 385-398.

6. Diaz MN, Frei B, Vita JA \& Keaney JF Jr. (1997) Antioxidants and atherosclerotic heart disease. $N$ Engl J Med 337, 408-416.

7. Mekki N, Dubois C, Charbonnier M, et al. (1997) Effects of lowering fat and increasing dietary fiber on fasting and postprandial plasma lipids in hypercholesterolemic subjects consuming a mixed Mediterranean-Western diet. Am J Clin Nutr 66, $1443-1451$

8. Nicolaiew N, Lemort N, Adorni L, Berra B, Montorfano G, Rapelli S, Cortesi N \& Jacotot B (1998) Comparison between extra virgin olive oil and oleic acid rich sunflower oil: Effects on postprandial lipemia and LDL susceptibility to oxidation. Ann Nutr Metab 42, 251-260.

9. Ramirez-Tortosa MC, Urbano G, Lopez-Jurado M, Nestares T, Gomez MC, Mir A, Ros E, Mataix J \& Gil A (1999) Extravirgin olive oil increases the resistance of LDL to oxidation more than refined olive oil in free-living men with peripheral vascular disease. J Nutr 129, 2177-2183.

10. Covas MI, Ruiz-Gutierrez V, De La Torre R, Kafatos A, Lamuela-Raventos RM, Osada J, Owen RW \& Visioli F (2006) Minor components of olive oil: Evidence to date of health benefits in humans. Nutr Rev 64, S20-S30.

11. Covas MI (2007) Olive oil and the cardiovascular system. PharmacolRes 55, 175-186.

12. Fernandez-Jarne E, Martinez-Losa E, Prado-Santamaria M, Brugarolas-Brufau C, Serrano-Martinez M \& Martinez-Gonzalez MA (2002) Risk of first non-fatal myocardial infarction negatively associated with olive oil consumption: a case-control study in Spain. Int J Epidemiol 31, 474-480.

13. Mata P, Varela O, Alonso R, Lahoz C, De Oya M \& Badimon L (1997) Monounsaturated and polyunsaturated n-6 fatty acidenriched diets modify LDL oxidation and decrease human coronary smooth muscle cell DNA synthesis. Arterioscler Thromb Vasc Biol 17, 2088-2095.

14. Esterbauer H, Gebicki J, Puhl H \& Jurgens G (1992) The role of lipid-peroxidation and antioxidants in oxidative modification of LDL. Free Radic Biol Med 13, 341-390.

15. Benzie IF (1996) Lipid peroxidation: a review of causes, consequences, measurement and dietary influences. Int J Food Sci Nutr 47, 233-261.

16. Delany JP, Windhauser MM, Champagne CM \& Bray GA (2000) Differential oxidation of individual dietary fatty acids in humans. Am J Clin Nutr 72, 905-911.

17. Reaven PD, Grasse BJ \& Tribble DL (1994) Effects of linoleate-enriched and oleate-enriched diets in combination with alpha-tocopherol on the susceptibility of LDL and LDL subfractions to oxidative modification in humans. Arterioscler Thromb 14, 557-566.

18. Fitó M, Covas MI, Lamuela-Raventos RM, Vila J, Torrents J, de la Torre C \& Marrugat J (2000) Protective effect of olive oil and its phenolic compounds against low density lipoprotein oxidation. Lipids 35, 633-638.

19. Fitó M, Covas MI, Lamuela-Raventos RM, Vila J, de la Torre C \& Marrugat J (2000) Olive oil and inhibition of low density lipoprotein oxidation. Role of phenolic compounds. Med Clin 115, 166-169.

20. Covas MI, de la Torre K, Farré-Albaladejo M, et al. (2006) Postprandial LDL phenolic content and LDL oxidation are molulated by olive oil phenolic compounds in human. Free Radic Biol Med 40, 608-616.

21. Marrugat J, Covas MI, Fito M, Schroder H, Miro-Casas E, Gimeno E, Lopez-Sabater MC, De La Torre R \& Farre M (2004) Effects of differing phenolic content in dietary olive oils on lipids and LDL oxidation - A randomized controlled trial. Eur J Nut 43, 140-147.
22. Visioli F \& Galli C (2002) Biological properties of olive oil phytochemicals. Crit Rev Food Sci Nutr 42, 209-221.

23. Ruano J, Lopez-Miranda J, Fuentes F, et al. (2005) Phenolic content of virgin olive oil improves ischemic reactive hyperemia in hypercholesterolemic patients. J Am Coll Cardiol 46, $1864-1868$

24. Fitó M, Gimeno E, Covas MI, Miro E, Lopez-Sabater MD, Farre M, De La Torre R \& Marrugat J (2002) Postprandial and short-term effects of dietary virgin olive oil on: Oxidant/ antioxidant status. Lipids 37, 245-251.

25. Gimeno E, Fito M, Lamuela-Raventos RM, Castellote AI, Covas M, Farre M, Torre-Boronat MC \& Lopez-Sabater MC (2002) Effect of ingestion of virgin olive oil on human low-density lipoprotein composition. Eur J Clin Nutr 56, 114-120.

26. Commission Regulation of 6 November 2003 amending Regulation (EEC) No. 2568/91 on the characteristics of olive oil and olive-pomace oil and on the relevant methods of analysis.

27. Gimeno E, Calero E, Castellote AI, Lamuela-Raventos RM, de la Torre MC \& Lopez-Sabater MC (2000) Simultaneous determination of alpha-tocopherol and beta-carotene in olive oil by reversed-phase high-performance liquid chromatography. J Chromatogr A 881, 255-259.

28. Swain T \& Hillis W (1969) The phenolic constituents of Prunus domestica. J Sci Food Agric 10, 63-68.

29. Gimeno E, Castellote AI, Lamuela-Raventos RM, de la Torre MC \& Lopez-Sabater MC (2002) The effects of harvest and extraction methods on the antioxidant content (phenolics, alpha-tocopherol, and beta-carotene) in virgin olive oil. Food Chem 78, 207-211.

30. Schroder H, Covas MI, Marrugat J, Vila J, Pena A, Alcantara M \& Masia R (2001) Use of a three-day estimated food record, a 72-hour recall and a food-frequency questionnaire for dietary assessment in a Mediterranean Spanish population. Clin Nutr 20, 429-437.

31. Elosua R, Garcia M, Aguilar A, Molina L, Covas MI \& Marrugat J (2000) Validation of the Minnesota leisure time physical activity questionnaire in spanish women. Investigators of the MARATDON Group. Med Sci Sports Exerc 32, $1431-1437$.

32. Havel RJ, Eder HA \& an Bragdan JH (2005) The distribution and chemical composition of ultracentrifugally separated lipoproteins in human serum. Clinical Investigation 34, $1345-1353$

33. Rodriguez-Palmero M, Lopez-Sabater MC, Castellote-Bargallo AI, de La Torre-Boronat MC \& Rivero-Urgell M (1997) Comparison of two methods for the determination of fatty acid profiles in plasma and erythrocytes. $J$ Chromatogr A 778, 435-439.

34. Gimeno E, Castellote AI, Lamuela-Raventos RM, de La Torre-Boronat MC \& Lopez-Sabater MC (2001) Rapid highperformance liquid chromatographic method for the simultaneous determination of retinol, alpha-tocopherol and betacarotene in human plasma and low-density lipoproteins. J Chromatogr B Biomed Sci Appl 758(2), 315-322.

35. Lamuela-Raventos RM, Covas MI, Fito M, Marrugat J \& de la Torre-Boronat MC (1999) Detection of dietary antioxidant phenolic compounds in human LDL. Clin Chem 45, 1870-1872.

36. Miró-Casas E, Albaladejo MF, Covas MI, Rodriguez JO, Colomer EM, Raventos RML \& De La Torre R (2001) Capillary gas chromatography-mass spectrometry quantitative determination of hydroxytyrosol and tyrosol in human urine after olive oil intake. AnalBiochem 294, 63-72.

37. Meisinger C, Baumert J, Khuseyinova N, Loewel H \& Koenig W (2005) Plasma oxidized low-density lipoprotein, a strong predictor for acute coronary heart disease events in apparently healthy, middle-aged men from the general population. Circulation 112, $651-657$. 
38. Visioli F, Galli C, Bornet F, Mattei A, Patelli R, Galli G \& Caruso D (2000) Olive oil phenolics are dose-dependently absorbed in humans. Febs Lett 468, 159-160.

39. Caruso D, Visioli F, Patelli R, Galli C \& Galli G (2001) Urinary excretion of olive oil phenols and their metabolites in humans. Metabolism 50, 1426-1428.

40. Miró-Casas E, Covas MI, Farre M, Fito M, Ortuno J, Weinbrenner T, Roset P \& De La Torre R (2003) Hydroxytyrosol disposition in humans. Clin Chem 49, 945-952.

41. Vissers MN, Zock PL, Roodenburg AJC, Leenen R \& Katan MB (2002) Olive oil phenols are absorbed in humans. $J$ Nutr 132, 409-417.

42. Fitó M, Cladellasc M, De La Torre R, et al. (2005) Antioxidant effect of virgin olive oil in patients with stable coronary heart disease: a randomized, crossover, controlled, clinical trial. Atherosclerosis 181, 149-158.

43. De La Torre-Carbot K, Chavez-Servin JL, Jauregui O, Castellote AI, Lamuela-Raventos RM, Fito M, Covas MI, MunozAguayo D \& Lopez-Sabater MC (2007) Presence of virgin olive oil phenolic metabolites in human low density lipoprotein fraction: Determination by high-performance liquid chromatography-electrospray ionization tandem mass spectrometry. Anal Chim Acta 583, 402-410.

44. Bonanome A, Pagnan A, Caruso D, et al. (2000) Evidence of postprandial absorption of olive oil phenols in humans. Nutr Metab Cardiovasc Dis 10, 111-120.

45. O'Byrne DJ, O'Keefe SF \& Shireman RB (1998) Low-fat, monounsaturated-rich diets reduce susceptibility of low-density lipoproteins to peroxidation ex vivo. Lipids 33, 149-156.

46. Gutteridge JMC (1995) Lipid-peroxidation and antioxidants as biomarkers of tissue-damage. Clin Chem 41, 1819-1828.

47. Covas MI, Fito M, Lamuela-Raventos RM, Sebastia N, De la Torre-Boronat C \& Marrugat J (2000) Virgin olive oil phenolic compounds: Binding to human low density lipoprotein (LDL) and effect on LDL oxidation. Int J Clin Pharmacol Res 20, $49-54$.

48. Soler-Rivas C, Espin JC \& Wichers HJ (2000) Oleuropein and related compounds. J Sci Food Agric 80, 1013-1023.

49. Espin JC, Soler-Rivas C, Cantos E, Tomas-Barberan FA \& Wichers HJ (2001) Synthesis of the antioxidant hydroxytyrosol using tyrosinase as biocatalyst. J Agric Food Chem 49, 1187-1193.

50. Masella R, Vari R, D’Archivio M, Di Benedetto R, Matarrese P, Malorni W, Scazzocchio B \& Giovannini C (2004) Extra virgin olive oil biophenols inhibit cell-mediated oxidation of LDL by increasing the mRNA transcription of glutathione-related enzymes. J Nutr 134, 785-791.

51. Turner R, Etienne N, Alonso MG, de Pascual-Teresa S, Minihane AM, Weinberg PD \& Rimbach G (2005) Antioxidant and anti-atherogenic activities of olive oil phenolics. Int $J$ VitamNutr Res 75, 61-70.
52. Stupans I, Kirlich A, Tuck KL \& Hayball PJ (2002) Comparison of radical scavenging effect, inhibition of microsomal oxygen free radical generation, and serum lipoprotein oxidation of several natural antioxidants. J Agric Food Chem 50, 2464-2469.

53. Moreno JA, Lopez-Miranda J, Gomez P, Benkhalti F, el Boustani ES \& Perez-Jimenez F (2003) [Effect of phenolic compounds of virgin olive oil on LDL oxidation resistance]. Med Clin 120, 128-131

54. Visioli F, Poli A \& Galli C (2002) Antioxidant and other biological activities of phenols from olives and olive oil. Med Res Rev 22, 65-75.

55. Palmerini CA, Carlini E, Saccardi C, Servili M, Montedoro G \& Arienti G (2005) Antagonism between olive oil phenolics and nitric oxide on lymphomonocyte cytosolic calcium. Mol Cell Biochem 280, 181-184.

56. Visioli F \& Galli C (1998) Olive oil phenols and their potential effects on human health. J Agric Food Chem 46, 4292-4296.

57. Weinbrenner T, Fito M, De La Torre R, et al. (2004) Olive oils high in phenolic compounds modulate oxidative/antioxidative status in men. J Nutr 134, 2314-2321.

58. Masella R, Di Benedetto R, Vari R, Filesi C \& Giovannini C (2005) Novel mechanisms of natural antioxidant compounds in biological systems: involvement of glutathione and glutathione-related enzymes. J Nutr Biochem 16, 577-586.

59. Morton LW, Caccetta RA, Puddey IB \& Croft KD (2000) Chemistry and biological effects of dietary phenolic compounds: Relevance to cardiovascular disease. Clin Exp Pharmacol Physiol 27, 152-159.

60. Zern TL \& Fernandez ML (2005) Cardioprotective effects of dietary polyphenols. J Nutr 135, 2291-2294.

61. Miles EA, Zoubouli P \& Calder PC (2005) Differential antiinflammatory effects of phenolic compounds from extra virgin olive oil identified in human whole blood cultures. Nutrition 21, 389-394.

62. Covas MI, Nyyssonen K, Poulsen HE, et al. (2006) The effect of polyphenols in olive oil on heart disease risk factors: a randomized trial. Ann Intern Med 145, 333-341.

63. Salvini S, Sera F, Caruso D, et al. (2006) Daily consumption of a high-phenol extra-virgin olive oil reduces oxidative DNA damage in postmenopausal women. Brit J Nutr 95, $742-751$

64. Visioli F, Bogani P, Grande S \& Galli C (2004) Olive oil and oxidative stress. Grasas Aceites 55, 66-75.

65. Perez-Jimenez F, de Cienfuegos GA, Badimon L, et al. (2005) International conference on the healthy effect of virgin olive oil - Consensus report, Jaen (Spain) 2004. Eur J Clin Invest 35, 421-424.

66. Estruch R, Martinez-Gonzalez MA, Corella D, et al. (2006) Effects of a Mediterranean-style diet on cardiovascular risk factors - A randomized trial. Ann Intern Med 145, 1-11. 